\title{
OÜRICÚRI
}

\section{A IMPORTÂNCIA DO LÚDICO NO PROCESSO DE DESENVOLVIMENTO DA CRIANÇA}

\author{
Roberto Remígio FLORÊNCIO ${ }^{*}$; Cristiane Coelho RODRIGUES ${ }^{2}$ \\ Marcleide Sá Miranda OLIVEIRA ${ }^{3}$
}
1 Instituto Federal de Educação do Sertão Pernambucano, Campus Zona Rural, Petrolina-PE - Doutorando em Educação - Universidade Federal da Bahia, Salvador-BA. *Autor correspondente. E-mail: betoremigio@yahoo.com.br
2Universidade Federal do Vale do São Francisco. E-mail: cristiane-coelho2@hotmail.com
${ }^{3}$ Secretaria Municipal de Educação Cultura e Esporte de Petrolina, Petrolina-PE. E-mail: marcleide.sa@hotmail.com
Recebido: 10.07.2019 Aceito: 20.12.2019
http://doi.org/10.29327/ouricuri.9.2-8

\begin{abstract}
Resumo: O presente trabalho faz uma abordagem sobre a importância do lúdico no processo de ensino e aprendizagem das crianças na Educação Infantil, utilizando como metodologia a revisão bibliográfica, onde foram utilizados livros, artigos e outros materiais publicados e atualizados, tendo como base autores que apontam como o lúdico pode ser um objeto facilitador na aquisição do conhecimento da criança nos primeiros anos de vida escolar, entre eles. A abordagem busca relacionar as brincadeiras lúdicas na Educação Infantil com o desenvolvimento e aprendizagem da criança. A pesquisa faz também uma reflexão sobre a teoria e a prática pedagógica desenvolvida em sala de aula, dando ênfase ao lúdico, como ferramenta no ensino-aprendizagem, complementando-se com conceito e historicidade do lúdico, além de uma breve abordagem sobre o desenvolvimento infantil. $O$ que se pretendeu no estudo foi compreender e refletir sobre a importância da ludicidade no processo educacional infantil das séries iniciais. Concliu-se que o lúdico, importante ferramenta na educação escolar infantil, é defendido por diversos estudiosos contemporâneos, e se constitui em instrumento indispensável como estratégia de ensinoaprendizagem, por se relacionar diretamente com o mundo das crianças.
\end{abstract}

Palavras-chave: Ludicidade; Infância; Aprendizagem.

\section{THE IMPORTANCE OF PLAYERS IN THE CHILD'S DEVELOPMENT PROCESS}

\begin{abstract}
The present work deals with the importance of the playful in the process of teaching and learning of children in Early Childhood Education, using as a methodology the bibliographic review, where books, articles and other published and updated materials were used, based on authors who point out the playfulness can be a facilitating object in the acquisition of children's knowledge in the first years of school life, among them. The approach seeks to relate the playful games in Early Childhood Education with the development and learning of the child. The research also makes a reflection on the theory and pedagogical practice developed in the classroom, emphasizing the playful as a tool in teaching-learning, complementing with the concept and historicity of the playful, as well as a brief approach on child development. What was intended in the study was to understand and reflect on the importance of playfulness in the early childhood education process. It was concluded that play, an important tool in early childhood education, is defended by several contemporary scholars, and constitutes an indispensable instrument as a teaching-learning strategy, because it relates directly to the world of children.
\end{abstract}

Keywords:Playfulness; Childhood; Learning. 


\section{LA IMPORTANCIA DE LOS JUGADORES EN EL PROCESO DE DESARROLLO DEL NIÑO}

Resumen: El presente trabajo aborda la importancia de la diversión en el proceso de enseñanza y aprendizaje de los niños en Educación Infantil, utilizando como metodología la revisión bibliográfica, donde se usaron libros, artículos y otros materiales publicados y actualizados, basados en autores que Señale cómo el juego puede ser un objeto facilitador en la adquisición del conocimiento de los niños en los primeros años de la vida escolar, entre ellos. El enfoque busca relacionar los juegos lúdicos en la educación de la primera infancia con el desarrollo y el aprendizaje del niño. La investigación también reflexiona sobre la teoría y la práctica pedagógica desarrollada en el aula, haciendo hincapié en el juego, como una herramienta en la enseñanza-aprendizaje, que se complementa con el concepto y la historicidad del juego, además de un breve enfoque sobre el desarrollo infantil. Lo que se pretendía en el estudio era comprender y reflexionar sobre la importancia del juego en el proceso educativo de los niños en los primeros grados. Se concluyó que el juego, una herramienta importante en la educación escolar de los niños, es defendido por varios académicos contemporáneos y constituye un instrumento indispensable como estrategia de enseñanza-aprendizaje, ya que se relaciona directamente con el mundo de los niños.

Palabras clave: Lúdico; Infancia; Aprendizaje.

\section{INTRODUÇÃO}

A função dos jogos e das brincadeiras lúdicas na Educação Infantil tem sido bastante discutida no âmbito da produção técnico-científica, principalmente quando se trata da relação entre os jogos de brincadeiras e o desenvolvimento físico-motor da criança. Os estudos partem do ponto de vista antropológico e tem seu foco principal nas análises dos jogos enquanto processo histórico, a partir da imagem da Kishimoto (2003).

Estudos a respeito levam em consideração, principalmente, a vivência cotidiana determinada pelo ambiente vivenciado pela criança. Neste sentido, o lugar onde as crianças habitam forma o seu contexto sociocultural e o tipo de educação permitida a ela. As relações que ela vivencia com as pessoas de seu convívio é que permitem a compreensão do cotidiano infantil. É, portanto, por meio dessa compreensão que se constrói a imagem da criança e a determinação de sua forma de brincar. Uma vez que cada indivíduo tem o seu cotidiano marcado por uma grande diversidade de valores que caracterizam suas ações sociais e o processo cultural de cada época dentro da construção das pessoas que fazem parte do contexto social. Kishimoto (2003) define a participação do sujeito em sua vida cotidiana quando envolve todos os seguimentos da vida e permite a construção de sua própria individualidade. Tais aspectos contribuem para o funcionamento dos sentidos, capacidade intelectual, paixões, ideias e habilidades manipulativas.

Surgiu assim a vontade de investigar a contribuição das brincadeiras lúdicas na Educação Infantil como elo entre os problemas e a solução, orientando o trabalho dos professores de Educação Infantil nos resultados do desenvolvimento de seus alunos. Desse modo, o objetivo principal desta pesquisa é compreender a importância das brincadeiras lúdicas, como recurso pedagógico na Educação Infantil e, especificamente, identificar as interferências que as brincadeiras lúdicas proporcionam à criança na infância. Por isso, acreditamos que o estudo é de 
grande relevância para a comunidade científica porque poderá propiciar aos leitores a superação de algumas lacunas sobre a utilização dos jogos e brincadeiras lúdicas na Educação Infantil, assim como auxiliar os professores no processo de interação e aprendizagem das crianças e na construção de ações lúdicas para a prática docente.

A abordagem sobre a importância da ludicidade na Educação Infantil deixa claro que o desenvolvimento cognitivo, afetivo e psicomotor das crianças, que desde pequenas têm participação ativa no cotidiano escolar, permite crianças ativas no seu próprio processo educativo, pois elas constituem uma imagem positiva de si, atuando no meio de forma independente e curiosa, na medida em que se percebem como integrantes transformadoras deste ambiente.

\section{O lúdico na aprendizagem: relação teoria e prática}

O processo de aquisição do conhecimento envolve sujeitos, organização, planejamento, instrumentos e ferramentas didático-pedagógicas, entre outros elementos imprescindíveis ao desenvolvimento da prática pedagógica, cujo objetivo principal é a aprendizagem, que só acontece de forma significativa quando os sujeitos envolvidos estão preparados e motivados para enfrentar o desafio de ensinar e aprender, considerando que a aprendizagem deve ser um processo ativo e dinâmico em que os indivíduos não são simples receptores passivos, mas processadores ativos da informação.

Na Educação Infantil, o professor exerce um papel de grande importância na contribuição do desenvolvimento, considerando que é ele quem vai auxilar no processo de construção do conhecimento da criança e, por isso, precisa compreender como se dá essa construção em cada estágio de desenvolvimento e num processo de interação, agir como mediador entre o educando e o conhecimento. Soares (2010) defende que o professor, além de conhecer as teorias,

precisa estabelecer um intercâmbio constante entre o conhecimento teórico e a prática pedagógica, uma vez que, sua mediação é exercida através de uma prática pedagógica construída com cada momento do processo, em cada circunstância específica em que ele ocorre, de acordo com história pessoal de cada criança (p. 43).

Isso implica dizer que o professor precisa estar preparado, ter uma formação adequada, ter o conhecimento teórico e aplicá-lo na sua prática pedagógica. É fundamental a este ter o conhecimento teórico consistente para saber fazer a mediação, para identificar o que a criança já sabe e partir desse conhecimento para uma evolução a outros níveis de aprendizagem. Deve-se considerar que cada criança é única, tem sua própria história e precisa apreender de maneira prazerosa, motivadora, instigante, posto que, "o professor deve estimular a criança, valorizando e acreditando que ela é capaz de aprender" (Soares, 2010, p. 45). O professor deve procurar envolvêla num clima de afeto para despertar o prazer de descobrir, vivenciar, construir, reconstruir, confiar, ter expectativa positiva, proporcionando à criança uma aprendizagem significativa. 
Os indivíduos experimentam durante todo o seu ciclo vital, situações em que precisam repetir atividades para concluir o fazer ou o refazer de algo necessário como: relacionar-se com o outro, trabalhar, estudar, construir, interagir. Aprender é interação. A aprendizagem é uma soma de experiências vividas pelo indivíduo no decorrer da sua vida (Florêncio, 2018). É um processo de interação em que, quem aprende, por necessidade ou por prazer, também ensina, segundo Freire (1978). Compreende-se, portanto, que não há limite no processo de aprendizagem, desde que o ser aprendiz tenha sido estimulado, motivado a aprender. Todos os indivíduos, à sua maneira e tendo em conta as suas características pessoais, são capazes de aprender a aprender. Isto é, capazes de encontrar respostas para situações ou problemas, quer mobilizando conhecimento de experiências anteriores em situações idênticas, quer projetando no futuro uma ideia ou solução que tem no presente, interagindo com os estímulos (situações e problemas) de uma forma pessoal.

O termo aprendizagem é tão abrangente que não é possível uma definição precisa. Entende-se, porém, que só é possível percebê-la, observando seus efeitos que aparecem na mudança de comportamento do indivíduo, pois quando se aprende, as atitudes, os hábitos, as posturas apresentam modificações significativas no indivíduo. Assim, educadores devem estar sempre procurando, através da formação continuada, encontrar caminhos que os conduzam as efetivações da aquisição do conhecimento, do saber científico, da mudança de comportamento dos seus alunos, posto que, segundo Fonseca (1995), a aprendizagem constitui-se em uma transformação comportamental.

A aprendizagem constitui uma mudança de comportamento resultante da experiência. Trata-se de uma mudança de comportamento ou de conduta que assume várias características. É uma resposta modificada, estável e durável, interiorizada e consolidada no próprio cérebro do indivíduo (p. 127).

A abordagem sociointeracionista concebe a aprendizagem como um fenômeno que se realiza na interação com o outro e acontece por meio da internalização, a partir de um processo, anterior, de troca, que possui uma dimensão coletiva. Nessa perspectiva, Vygotsky (1998) diz que

[...] a aprendizagem deflagra vários processos internos de desenvolvimento mental, que tomam corpo somente quando o sujeito interage com objetos e sujeitos em cooperação. Uma vez internalizados, esses processos tornamse parte das aquisições do desenvolvimento (p. 75).

Assim, um processo interpessoal é transformado num processo intrapessoal. Todas as funções no desenvolvimento da criança aparecem duas vezes no ciclo do desenvolvimento humano: primeiro, no nível social, e depois, no nível individual; primeiro, entre pessoas (interpsicológica), e depois, no interior da criança (intrapsicológica). Isso se aplica igualmente para a atenção voluntária, para a memória lógica e para a formação de conceitos, uma vez que: 
Todas as funções superiores originam-se, das relações reais entre indivíduos humanos. Existem dois níveis de conhecimento: o real e o potencial. No primeiro o indivíduo é capaz de realizar tarefas com independência, e caracteriza-se pelo desenvolvimento já consolidado. No segundo, o indivíduo só é capaz de realizar tarefas com a ajuda do outro, o que denota desenvolvimento, porque não é em qualquer etapa da vida que um indivíduo pode resolver problemas com a ajuda de outras pessoas (Vygotsky, 1998, p. 75).

Partindo desses dois níveis, Vygotsky (1998) define a Zona de Desenvolvimento Proximal (ZDP) como a distância entre o conhecimento real e o potencial; nela estão as funções psicológicas ainda não consolidadas. E assim esclarece:

Ela é a distância entre o nível de desenvolvimento real, que se costuma determinar através da solução independente de problemas, e o nível de desenvolvimento potencial, determinado através da solução de problemas sob a orientação de um adulto ou em colaboração com companheiros mais capazes (p. 112).

Faz-se necessário observar o ritmo de aprendizagem de cada aluno de maneira individual, pois esta não ocorre de maneira uniforme, uma vez que as turmas de alunos são compostas por sujeitos de origens e meios socioculturais diferentes em que alguns aprendem com maior facilidade, outros demonstram certa lentidão e por isso, precisam de auxílio. A orientação do professor ou de colegas com melhor desempenho, diante de situações-problemas, se constitui em estímulo e motivação para o aluno com maior dificuldade de aprender para superar as suas dificuldades. Portanto:

A noção de motivação está também intimamente ligada à noção de aprendizagem. A estimulação e a atividade em si não garantem que a aprendizagem se opere. Para aprender é necessário estar motivado e interessado. A ocorrência da aprendizagem depende não só do estímulo apropriado, como também de alguma condição interior própria do organismo ("sede", "curiosidade", etc.) (Fonseca, 1995, p. 131).

Enfim, as experiências vividas em contextos diferentes, a história de vida e de mundo dos sujeitos são elementos de fundamental importância no processo de aprendizagem, pois o relacionamento do conhecimento formal com as experiências faz com que o educando atinja o crescimento pessoal.

$\mathrm{Na}$ infância, mais especificamente no primeiro período da vida humana, que se estende até por volta dos seis, sete anos de idade, fase da vida em que acontece o desenvolvimento intelectual e sensório-motor, o processo de aprendizagem deve acontecer de forma que a criança sinta prazer, alegria, satisfação e interesse, despertados por atividades lúdicas. Nesta fase de vida a criança gosta de brincar e na interação com outras crianças, com outras pessoas inicia seu processo de construção de representações e atribuição de significados a sua realidade. Por isso: 
São muito importantes nesta fase os momentos de brincadeiras, de faz de conta e as histórias contadas e/ou representadas, que proporcionam excelentes ganhos na oralidade das crianças. Mais que isso, são fundamentais e são garantidas diariamente em suas rotinas, pois Ihes asseguram melhor desenvolvimento emocional, cognitivo e cultural (Soares, 2010, p. 16).

A capacidade motora da criança se desenvolve na fase operacional em que ela realiza tarefas como pintar, rabiscar, cortar, realizando movimentos com as mãos. Nessa fase também, a criança é bastante inquieta e, por isso, corre, pula, sobe, desce, enfim, a motricidade se revela na criança.

Fica entendido que o desenvolvimento motor, como o ato de cortar uma linha com tesoura, dobrar papel, colorir, copiar um quadrado, se dá na idade em que a criança frequenta a pré-escola. Daí a necessidade de se trabalhar as atividades lúdicas direcionadas com o intuito de facilitar este processo necessário ao aprendizado da leitura e da escrita propriamente (Constato e Sponda, 2009, p. 18).

Nesse sentido, todo o trabalho pedagógico deve ser adequado ao desenvolvimento psicomotor da criança e o lúdico explorado pedagogicamente, na prática. As atividades lúdicas precisam ser vivenciadas de modo a contribuir, concretamente, na realização das tarefas específicas para a criança da Educação Infantil, sobretudo porque:

O Referencial Curricular Nacional para a Educação Infantil (MEC, 1988) estabelece a brincadeira como um de seus princípios norteadores que a define como um direito da criança que, garante seu desenvolvimento, sua interação social, além de situá-la na cultura em que está inserida. As atividades de brincadeira na educação Infantil são praticadas há muitos anos, entretanto, torna-se imprescindível que o professor distinga o que é brincadeira livre e o que é atividade pedagógica com aspectos lúdicos (Branco et al., 2006, p. 44).

Dessa forma, o lúdico é um instrumento de inegável valor, uma vez que, está relacionado à infância e o que a criança mais aprecia é brincar. Então, o papel do professor da Educação Infantil é transformar a brincadeira em conhecimento, em significados para que a criança possa progredir, evoluir, aprender brincando; desenvolver o cognitivo, a motricidade e adquirir habilidades e competências necessárias, através da utilização de recursos lúdicos adequados e atrativos, pois: "[...] O lúdico é uma atividade séria que não tem consequências frustrantes para a criança, e pode ser usado como material didático para o ensino" (Aranão, 1996, p. 20).

Não se pode conceber a prática pedagógica do docente da Educação Infantil sem a utilização de recursos e instrumentos lúdicos, pois a própria criança é lúdica, dessa forma, a escola e o professor, também precisam ser lúdicos e devem desenvolver uma prática pedagógica que favoreçam a aprendizagem e a formação integral da criança, fazer com que a criança aprenda os valores humanos, perceba os limites para cada ação, uma vez que: 
[...] é preciso acostumar nossas crianças a cumprir regras simples, dentro de um modelo bem planejado, sem exageros, mas que permita à criança exercitar-se e adquirir condições de preparar-se para a realidade - os muitos "nãos" que, com certeza, a vida vai-lhe mostrar, as muitas regras que vai encontrar (Rossini, 2001, p. 25).

O lúdico como ferramenta educativa, fornece subsídios para que pais e professores, como educadores e como promotores de aprendizagens, possam trabalhar com a criança diversas regras, dependendo da atividade, visando a formação da criança e a sua aprendizagem, não apenas dos conteúdos curriculares da educação escolar, mas o respeito pelo outro. O saber esperar a sua vez, a sensibilidade e solidariedade, a cooperação, o autocontrole, enfim, competências que o indivíduo precisa desenvolver, desde a infância. Porém, por meio de um trabalho bem conduzido, bem direcionado, de forma que os efeitos sejam percebidos em situações futuras.

Trabalhar o lúdico como fonte do saber e instrumento que favorece a aprendizagem, o desenvolvimento afetivo e social da criança, estimulá-la a conhecer, a aprender os conteúdos necessários ao prosseguimento dos seus estudos, torna-se um dever da escola e responsabilidade do professor que deseja alcançar objetivos precisos no processo de desenvolvimento e de aprendizagem das crianças da Educação Infantil.

\section{Desenvolvimento infantil}

Segundo Soares (2010), Piaget identifica quatro períodos de desenvolvimento da criança, que têm variações entre a idade cronológica e o estágio de desenvolvimento, dependendo dos estímulos que recebe e das características genéticas e/ou ambientais, ou seja, dependendo dos estímulos que recebe dos pais, da escola e dos espaços que a criança frequenta.

Tais períodos podem ser identificados como sensório-motor, que compreende o período de vida de 0 a 2 anos de idade, o período pré-operatório, dos 2 aos 7 anos e o período concreto, de 7 aos 12 anos. Assim, segundo Piaget, as primeiras imagens mentais aparecem a partir dos 2 anos, na imitação diferida. Soares (2010) esclarece que é nessa fase que começam as brincadeiras de faz de conta, em que a criança finge por ser isto ou aquilo. Comenta ainda que é a chamada jogo simbólico, com o qual ela procura satisfazer os próprios desejos, na busca do domínio das situações; tudo como a criança quiser, na busca dos seu prazer de descobrir o mundo, de se descobrir.

Nessa fase, a criança começa a desenvolver a coordenação motora, a interagir com outras crianças de maneira mais consciente, a reconhecer a emoção de outras pessoas e por isso, precisa ser estimulada por meio da conversa, dos movimentos. É importante que a criança ouça música, dance, rabisque, manuseie brinquedos, quando estimulada e repete atividades, na tentativa de fazer imitações. 
De acordo com Soares (2010, p. 16), a criança, nessa fase, apresenta pensamento egocêntrico, surgindo, contudo, outra forma de organização mental que possibilita à mesma relacionar-se com a realidade de uma maneira diferente da qual se relacionava antes.

Ainda de acordo com Soares (2010), dos três até os seis anos de idade, a criança vai evoluindo, passando a utilizar a linguagem, a interação, a comunicação, atribuindo significados importantes à sua realidade, ocorrendo modificações nos seus aspectos cognitivos, afetivos, psicológicos e culturais. Nessa fase, os brinquedos passam a ter um valor simbólico imprescindível e a imaginação mais aguçada, permite que a criança recrie a realidade, numa tendência lúdica, que confunde realidade e fantasia. Somente a partir dos sete anos de idade, a realidade da criança passa a ser mais estruturada pela razão do que pela assimilação egocêntrica. A criança passa a sentir necessidade de explicar logicamente suas ideias e ações, substituindo a tendência lúdica do pensamento por atitudes críticas (Soares, 2010, p. 16).

Assim, o professor de Educação Infantil precisa ter o conhecimento necessário a respeito dos estágios de desenvolvimento da criança, para compreender as formas de estímulo que precisam ser aplicados na prática, para que consiga avançar no processo do ensino e da aprendizagem.

\section{METODOLOGIA}

Após estudos e reflexões iniciais sobre o tema surge a pergunta de pesquisa com foco no pensamento dos estudiosos a respeito da ludicidade, do lúdico e do uso deste como metodologia de aprendizagem, considerando a necessidade de fazer uma abordagem sobre o lúdico como importante ferramenta no processo de ensino-aprendizagem de crianças da Educação Infantil. Por essa razão, optou-se pela pesquisa de natureza bibliográfica, elaborando o texto a partir do tema proposto, em que se discute o lúdico como um suporte concreto que pode estimular a criança, uma vez que a brincadeira e o brinquedo tem ligação com a infância e por meio destes a criança, entre o real e o imaginário, identifica-se, podendo ser considerada portanto uma estratégia de ensino viável. Fez-se uma abordagem dos aspectos relevantes, a fim de compreender a utilização de instrumentos lúdicos na prática pedagógica, possibilitando o desenvolvimento criativo, afetivo, intelectual e social da criança, que encontrará motivação para aprender com base na leitura, análise e reflexão, tendo como suporte diversos autores que tratam deste assunto de importância educacional e social.

Intencionando-se alcançar os objetivos elencados, seguiu-se a linha de Gil (2008, p. 65), cujo pensamento é de que, a pesquisa bibliográfica é desenvolvida a partir de material elaborado constituído principalmente de livros e artigos científicos. 
Dessa forma, o pesquisador adquire as informações seguras para refletir sobre elas, construindo conceitos e opiniões próprias com embasamento teórico eficaz aos propósitos da pesquisa, uma vez que as fontes pesquisadas são reconhecidas pelo domínio científico.

\section{Análise e contextualização do lúdico na educação infantil}

Discutir sobre o processo lúdico na Educação Infantil requer uma breve reflexão sobre o surgimento dessa palavra. O lúdico originou-se da palavra latina "ludus" que significa jogo. Esse conceito deixou de ser relacionado somente ao jogo devido a suas implicações relacionadas às necessidades lúdicas ultrapassarem as fronteiras do brincar espontâneo.

Estudos de Kishimoto (2003) registram a participação das pessoas no surgimento dos jogos, com o resgate das brincadeiras em diversos países, surgindo, assim, um novo olhar para a criança moderna e que as brincadeiras passam a serem vistas além do brincar.

O brinquedo educativo data dos tempos do Renascimento, mas ganha força com a expansão da Educação Infantil (Kishimoto, 2003). Entendido como recurso que educa, ensina e desenvolve de forma prazerosa o brinquedo educativo materializa-se no quebra-cabeça, destinado a ensinar formas ou cores, nos jogos de tabuleiro, que exigem a compreensão do número das operações matemáticas, nos brinquedos de encaixe, que trabalham sequência de tamanhos e de forma; nos múltiplos brinquedos e brincadeiras cuja concepção exigiu um olhar para o desenvolvimento infantil e materialização da função psicopedagogia.

Assim, são também os móbiles destinado à função visual, sonora ou motora carrinhos com pino que se encaixam para desenvolver a coordenação motora, parlendas para expressão da linguagem, brincadeiras envolvendo música e dança para a expressão motora, gráfica e simbólica (Kishimoto, 2003).

É importante ressaltar que, além das brincadeiras auxiliarem na construção da identidade cultural da criança, elas entram para o auge total, a partir dos enfoques que Piaget (1987) e Vygotsky (1998) deram as interações das crianças, por meio dos brinquedos. Ressalta-se também o aumento da difusão dos jogos didáticos nas escolas brasileiras, com a pedagogia dos jogos froebelinos. Esta prática foi adotada nos jardins de infância. "[...] Dessa perspectiva teve a noção de jogos livres nas brincadeiras cantadas, e de jogos orientados quando se utilizavam materiais como; bola, cilindro e o cubo" (Kishimoto, 2003 p. 99).

Pesquisas como a de Kishimoto (2003) discorre sobre as crianças do período colonial, descreve a imagem dos meninos no espaço de engenho de açúcar a maneira como eles brincavam, da descrição dessas brincadeiras surge a mistura das culturas e do desencadeamento dos jogos tradicionais.

Acredita-se que esses objetos citados pela a autora eram os mais usados da época, pois não havia tanta diversidade de jogos e matérias disponíveis para novas produções como 
atualmente. Mas, mesmo assim, buscou-se compreender como as crianças se relacionavam com o mundo e como elas produziam a sua própria cultura.

\section{O lúdico como ferramenta de ensino-aprendizagem na educação infantil}

De acordo com Piaget (1987), o jogo não pode ser visto só como divertimento, distração ou para passar o tempo. Nessa visão ele é um dos principais instrumentos que favorece ao desenvolvimento físico, cognitivo, afetivo e moral da criança.

Partindo desse pressuposto, as práticas educacionais devem estimular a inteligência e orientar o aluno a descobrir e inventar, o professor como mediador do conhecimento deve provocar na criança a necessidade do conceito que ele precisa reconstruir.

A fase inicial da vida escolar da criança é uma etapa importante na vida do ser humano, onde ela irá se deparar com o mundo do conhecimento. No entanto, a criança chega a escola com uma carga de saberes adquiridos em suas vivências sociais que devem ser levadas em conta pelo professor, que por sua vez deve ser compreensivo e tratar criança como criança.

Vygotsky (1998) revela por meio de seus estudos que o trabalho pedagógico requer a oferta de estímulos externos e a mediação do professor em outras situações que não jogos, em que alunos possam se desenvolver a partir da observação e da interação com o outro como propõe.

Conforme o discurso anterior, as práticas lúdicas não se resumem ao jogo ou ao brinquedo em si. Esse pensamento é bastante consolidado pela reflexão e interpretação que se faz do pensamento de Vygotsky sobre o desenvolvimento humano.

Segundo Kishimoto (2003) na análise do livro "Aprendizado e Desenvolvimento, um processo sócio cultural", organizado por Marta Kohl, é possível observar a preocupação do autor com o desenvolvimento do ser humano, ao percebê-lo como resultado de um processo históricosocial, além de expressar o interesse em compreender diversos aspectos do comportamento humano.

O brincar na Educação Infantil proporciona o desenvolvimento intelectual, emocional e social. Trabalhar o lúdico na sala de aula significa facilitar o desenvolvimento e a aprendizagem da criança. Os jogos e as brincadeiras lúdicas na escola executadas com a medição do professor fazem com que a criança aprenda construindo e desconstruindo. Brincando a criança consegue ter uma visaõ ampla sobre mundo.

O sentido real, verdadeiro, funcional da educação lúdica estará garantido se o educador estiver preparado para realizá-lo. Nada será feito se ele não tiver um profundo conhecimento sobre os fundamentos essenciais da educação lúdica, condições suficientes para socializar o conhecimento e predisposição para levar isso adiante (Almeida, 2002, p. 63). 
Trabalhar o lúdico na Educação Infantil não é uma tarefa fácil. Requer muito esforço e dedicação por parte do professor, que para conseguir alcançar o sucesso deve sempre estar procurando novos conhecimentos e inovando a sua forma de trabalhar com as crianças.

A ludicidade é uma maneira inovadora que faz a criança despertar para o mundo e se apropriar do saber. Para conseguir uma boa aprendizagem dos alunos o professor precisa ter um bom embasamento teórico, assim, conseguirá realizar uma boa prática.

\section{A contribuição dos jogos lúdicos para o desenvolvimento da criança}

Nenhuma criança brinca só para passar o tempo. Sua escolha é motivada por processos íntimos, desejos, problemas, ansiedades. Toda criança tem direito de brincar, e no âmbito escolar essas brincadeiras devem ser trabalhadas com propósito de aprendizagem. O lúdico não pode ser trabalhado apenas como um mero passatempo ou momento de distração para a criança. O brincar é um momento de desenvolvimento social, intelectual e motor, e fortalece as relações interpessoais e emocionais, fazendo com que a criança desenvolva todas as suas potencialidades.

Ao brincar de faz de conta a criança potencializa sua imaginação e se conhece. Por meio de símbolos exerce os papéis do que gostaria de ser quando crescer, onde cada objeto tem um significado. É muito interessante observar as crianças brincando de mãe e filha com as bonecas ou de casinha, médico, professor entre outros. Nessas brincadeiras de faz de conta, algumas crianças decidem o que querem ser na vida adulta. As brincadeiras simbólicas proporcionam 0 desenvolvimento imaginário da criança e oferece bons momentos que a satifaz.

A criança é, por natureza, lúdica. Brincar para ela é uma necessidade, com as brincadeiras elas aprendem a ter desenvolvimento de ritmo, agilidade, coordenação motora; despertam a observação, a criatividade, a instigar o diálogo, a esperar sua vez, a seguir regras, a negociar, a compartilhar. A brincadeira é um instrumento importante também no desenvolvimento da linguagem. Brinquedos e brincadeiras, quando bem conduzidos e orientados, são ferramentas eficazes para o aprendizado das crianças. Por isso, é importante que a escola desenvolva uma proposta pedagógica que contemple procedimentos e atividades lúdicas na prática docente de sala de aula para favorecimento de um convívio saudável, estimulando a criança em seu desenvolvimento, em sua aprendizagem, visto que:

Os estudos têm avançado e hoje fala-se em "atitude lúdica", isto é, a postura do educador com relação a todas as atividades propostas, perpassando tempos e espaços predefinidos para o brincar. Assumir uma atitude lúdica significa aprender e incorporar as linguagens expressivas das crianças e adotar essa postura em todos os conhecimentos e atividades (Friedmann, 1996, p. 46).

Nesse sentido, o professor, ao desenvolver uma atividade lúdica, ao observar o brincar das crianças, adquire a capacidade de conhecê-las por meio das atitudes durante a brincadeira, além 
das possibilidades de diversas aprendizagens por meio das atividades propostas. É importante salientar, que através das brincadeira das crianças, o professor poderá obter informações sobre o estágio do desenvolvimento destas, tanto nas brincadeiras individuais, como nas coletivas, além de auxiliá-la nas aprendizagens específicas, estimulando também as diversas aprendizagens.

Aprender é muito mais complexo para a criança, porque é um processo que exige concentração no objeto da aprendizagem, pois o desenvolvimento cognitivo dela também é complexo, visto que, passa por etapas de maturação e cada criança tem o seu tempo de aprender.

Para que a criança se interesse pelo conteúdo deve haver motivação, um despertar para a atenção dela, principalmente as que têm mais dificuldade em acompanhar o desenvolvimento das aulas e dos conteúdos. Por isso, é fundamental a ação do professor, no sentido de encontrar formas para facilitar a compreensão e a aprendizagem das crianças. Assim, o professor deverá estar ciente de que:

As atividades lúdicas são instrumentos altamente importantes, mais do que apenas divertimento, são um instrumento indispensável para o desenvolvimento do processo ensino aprendizagem, que propicia a obtenção de informações em perspectivas e dimensões que perpassam o desenvolvimento do educando. A ludicidade é uma tática insubstituível para ser empregada como estímulo no aprimoramento do conhecimento e no progresso das diferentes aprendizagens (Maluf, 2008, p. 42).

Existem conteúdos que exigem maior concentração e uso do raciocínio. Certamente, a maioria das crianças sentirão dificuldades e poderão perder o interesse por aprender, ocorrendo a dispersão, a indiferença e até indisciplina em sala de aula. Uma das formas que poderá atrair a atenção e o interesse do educando é a brincadeira com o objetivo de auxiliá-lo na construção da sua aprendizagem, pois está relacionada ao lúdico como uma forma de estimular o desenvolvimento cognitivo, afetivo, social, moral, linguístico e físico-motor e propiciar aprendizagens específicas" (Friedmann, 1996, p. 70).

Nesse sentido, o lúdico estimula a conhecer, a compreender, a interagir, a dialogar e a apreender os conhecimentos específicos, além de ajudar a criança a conhecer regras. Para isso, o professor deve organizar os conteúdos, principalmente os considerados mais complexos, planejar as atividades e deixar os alunos cientes dos objetivos da atividade lúdica que será aplicada. Assim, os alunos vão aprendendo, estimulados pela brincadeira ou pelo brinquedo, partindo do abstrato para o concreto.

Nessa perspectiva, o professor precisa ter experiência com Educação Infantil e saber quais brincadeiras melhor se adequam à idade das crianças, traçando objetivos claros e precisos para a sua aula, consciente de que não deverá ocupar todo o tempo pedagógico apenas desenvolvendo tais brincadeiras, a menos que haja uma diversificação e estejam relacionadas ao conteúdo que precisa ser vivenciado. Ter também o cuidado para que as crianças não façam opção apenas, pelas 
brincadeiras, uma vez que, a criança pequena gosta muito de usar o seu tempo, brincando. Motivála sempre a aprender, pois:

É de grande valor social, oferecendo possibilidades educacionais, pois, favorece o desenvolvimento corporal, estimula a vida psíquica e a inteligência, contribui para a adaptação ao grupo preparando para viver em sociedade, participando e questionando os pressupostos das relações sócias (Kishimoto, 1994, p. 13).

Nesse sentido, com atividades pedagógicas, envolvendo o lúdico, a criança muda hábitos, consegue se relacionar melhor com o seu grupo, interage com mais sociabilidade, além de melhorar a autoestima, pois aprende com mais facilidade, aumenta as possibilidades de avançar nos resultados e cria laços com o professor que deve manter-se sempre ativo para proporcionar ao aluno, por meio de atividades lúdicas, o despertar para:

[...] travar contato com desafios, buscar saciar a curiosidade de tudo, conhecer; representar as práticas sociais, liberar riqueza do imaginário infantil; enfrentar e superar barreiras e condicionamentos, ofertar a criação, imaginação e fantasia, desenvolvimento afetivo e cognitivo (Feijó, 1992, p. 185).

Dessa forma, o ensino com atividades pedagógicas envolvendo o lúdico, poderá marcar o início de uma mudança significativa nas práticas pedagógicas e o crescimento do aluno, no sentido de construir seu conhecimento, sua história, aguçar a imaginação e confrontá-la com a realidade do mundo que o cerca. Contudo, é preciso investir na formação do professor, prepará-lo para transformar a sala de aula num espaço apropriado para aquisição do conhecimento e a criança preparada para prosseguir com sucesso (Silva e Santos, 2017).

Evidentemente, o lúdico será uma ferramenta pedagógica de fundamental importância para despertar no educando o desejo de aprender, porém deve ser aplicado como uma estratégia, com planejamento e não deverá ser a única forma de ensinar.

Quando o professor realiza uma atividade lúdica na sala de aula o educando aprende de forma natural. Sem perceber, a criança desenvolve habilidades que refletirão na sua vida adulta. Quando a criança está brincando ela está se preparando para para a vida adulta.

A brincadeira na infância é indispensável. Brincar é uma forma da criança exercer o seu direito de ser criança e ser tratada como tal. As brincadeiras lúdicas na sala de aula fazem com que a criança tenha uma infância saudável e um bom rendimento escolar. Brincando, a criança expressa suas emoções e sentimentos.

Construindo, transformando e destruindo, a criança expressa seu imaginário, seus problemas e permite aos terapeutas o diagnóstico de dificuldades de adaptação bem como a educadores o estímulo da imaginação infantil e o desenvolvimento afetivo e intelectual. Dessa 
forma, quando está construindo, a criança está expressando suas representações mentais, além de manipular objetos (Kishimoto, 2005, p. 40).

\section{CONSIDERAÇÕES FINAIS}

A criança é um ser muito ativo. Dificilmente, o professor vai encontrar em sua sala de aula uma criança que não goste de brincar, de correr, pular, movimentar-se, constantemente. Essa energia que a criança tem consigo deve ser aproveitada pelo docente para atividades lúdicas que envolvam os movimentos, a psicomotricidade para que ela possa aprender a se expressar, a se comunicar corporalmente; utilizar os sentidos para educar as vontades compulsivas da criança como gritar e falar alto. Enfim, existem diversos meios de o professor trabalhar a ludicidade em sala de aula para promover a aprendizagem do educando.

O lúdico no processo de ensino aprendizagem é um instrumento de grande importância e está relacionado à criança. As brincadeiras podem e devem ser ferramentas que auxiliam na construção do conhecimento, na ajuda à criança a conhecer a si mesma, os seus limites e no despertar para a imaginação e a criatividade, propiciando à criança o prazer de aprender, sem que ela se sinta obrigada, como ocorre no ensino de forma tradicional.

Entretanto, as brincadeiras devem ser utilizadas pelo professor como instrumentos lúdicos de aprendizagem e não como passatempo ou apenas entretenimento. Por isso, o professor tem que preparar as suas aulas, planejar as atividades e ter, muito claros, os objetivos, relacionando as atividades lúdicas aos conteúdos que a criança precisa aprender.

Analisando o conteúdo pesquisado, chega-se a uma compreensão de que as atividades pedagógicas lúdicas devem ser adequadas à idade e ao nível de escolaridade da criança e o ensino aprendizagem deve visar sempre a formação integral dela, com perspectivas de futuro. Para isso, a escola precisa acompanhar as transformações que ocorrem, de forma rápida, nos diversos contextos; o professor precisa ser hábil e ter embasamento teórico para aplicar, na sua prática pedagógica em sala de aula; reconstruir, considerando a necessidade de enfrentar os desafios de realizar um trabalho pedagógico, utilizando o lúdico, de maneira atrativa.

Desse modo, esse estudo buscou investigar o lúdico em sala de aula como ferramenta pedagógica, que possibilite à criança aprender e desenvolver suas potencialidades, estimuladas por uma prática pedagógica em que o professor crie condições que motivem a criança a aprender brincando.

Ao realizar a análise dos textos selecionados, concluímos que o lúdico é de fundamental importância para a aprendizagem e para o desenvolvimento da criança. Relacionando-se os recursos didáticos pedagógicos, neste caso os brinquedos, aos conteúdos curriculares, percebe-se a necessidade dos docentes utilizá-los de forma integrada, tendo a oportunidade de vivenciar experiências novas, ensinar e aprender com as crianças. 
Constatou-se que o lúdico como ferramenta na educação escolar é defendido por vários estudiosos, como sendo um instrumento que favorece ao educando possibilidades de aprendizagem, uma vez que este se relaciona com a vida da criança.

Por fim, concluímos que é possível avançar no desempenho e rendimento escolar dos educandos com a utilização de recursos didático-pedagógicos lúdicos que ajudarão, sem dúvida, aos docentes superar diversos desafios da alfabetização de crianças, construindo uma aprendizagem eficaz e significativa.

\section{REFERÊNCIAS}

Almeida, M. E. PROINFO: Informática e formação de professores. Secretaria de Educação à Distância. Brasília: MEC Seed, v. 2, 2002.

Aranão, I. V. T. A matemática através de brincadeiras e jogos. Campinas-SP: Papirus, 1996.

Branco, A. V. Maciel D. A.; Queiroz, N. L. M. Brincadeira e desenvolvimento infantil: um olhar sociocultural construtivista. Paideia, 16(34), 169-179, 2006.

Constato, E. P. M.; Sponda, E. A relação entre atividade lúdica na pré-escola de Colégios particulares. Artigo. Revista Interface: ensino, pesquisa e extensão. Ano 1, no 1. Suzano-SP: 2009.

Feijó, O. G. O corpo em movimento: Uma psicologia para o esporte. Rio de Janeiro: Shape, 1992.

Florêncio, R. R. (2018). Blog Etnolinguagens. Disponível em: www.etnolinguagens.webnode.com. Acesso em: 10 de fev. 2019.

Fonseca, V. Introdução às dificuldades de aprendizagem. - 2 ed. rev. aum. - Porto Alegre: Artes Médicas, 1995.

Freire, P. (1978). Pedagogia do Oprimido. 30. Ed. Campinas: Vozes, 2012.

Friedman, A. Brincar, crescer e aprender: o resgate do jogo infantil. São Paulo: Moderna, 1996.

Gil, A. C. Métodos e Técnicas de pesquisa social. 6ae edição. Atlas: São Paulo, 2008

Kishimoto, T. M. O jogo e a educação infantil. São Paulo: Pioneira, 1994.

Kishimoto, T. M. Jogos infantis: o jogo, a criança e a educação. 3 ed. São Paulo: Cortez, 2003.

Kishimoto, T. M. Jogo, brinquedo, brincadeira e a educação. 11. ed. São Paulo: Cortez, 2005.

Maluf, A. C. M. Atividades lúdicas para a Educação Infantil: Conceitos, orientações e práticas. 1a ed. Petrópolis: Vozes, 2008.

Piaget, J. Aprendizagem e Conhecimento. In.: Aprendizagem e conhecimento. Tradução Equipe da Livraria Freitas Bastos. Rio de Janeiro: Freitas Bastos, 1987.

Rossini, M. A. S. Pedagogia afetiva. Petrópolis, Rio de Janeiro: Vozes, 2001.

Silva, C. M. S. Santos, C. A. B. Uma reflexão sobre a importância dos jogos e brincadeiras na escola, Revista Atlante: Cuadernos de Educación y Desarrollo, v. junio, p. 1-12, 2017.

Soares, M. I. B. Alfabetização Linguística: da teoria à prática. Belo Horizonte: Dimensão, 2010

Vygotsky, L. S. A formação social da mente. São Paulo: Fontes, 1989.

Vygotsky, L. S. A formação social da mente. 33. ed. São Paulo: Fontes, 1998. 